\title{
Photoswitching in azo dyes bearing thienylpyrrole and benzothiazole heterocyclic
} systems

\author{
Paulo J. Coelho ${ }^{a}$, M. Cidália R. Castro ${ }^{b}$, A. Maurício C. Fonseca ${ }^{b}$, M. Manuela M. Raposo ${ }^{b}$ \\ ${ }^{a}$ Centro de Química, Vila Real, Universidade de Trás-os-Montes e Alto Douro, 5001-801 Vila Real, \\ Portugal.
}

${ }^{\mathrm{b}}$ Centro de Química, Universidade do Minho, Campus de Gualtar, 4710-057 Braga, Portugal.

Dedicated to the Centenary of the Portuguese Chemical Society

\begin{abstract}
Visible light promotes the conversion of the E-isomer of benzothiazol-2-yl and benzothiazol-6-yl diazenes to the thermal unstable $Z$-isomer that reverts in few seconds to the initial form. The kinetics of the thermal Z-E process is strongly influenced by the linkage position of the $\mathrm{N}=\mathrm{N}$ function to the benzothiazole heterocycle. Thienylpyrrole azo dyes functionalized with benzothiazol-6-yl groups are particularly interesting since they show an excellent compromise between the switching speed (rate constants: $0.068-0.12 \mathrm{~s}^{-1}$ ) and the amplitude of the absorbance variation $(37-42 \%)$.
\end{abstract}

Keywords: Photochromism; heterocyclic azo dyes; benzothiazole; pyrrole; thiophene; UV/vis spectroscopy; photoswitching. 


\section{Introduction}

Diaryl azo dyes substituted at the 4 and $4^{\prime}$ positions with electron-donating and electronwithdrawing groups (called a 'push/pull' substitution pattern) are characterized by a strong asymmetric electron distribution. These "pseudo-stilbenes" display a strong and broad absorption band in the visible region and the colour exhibited by these chromophores can be controlled by the appropriate choice of substituents. Due to the asymmetric electron distribution they possess important nonlinear optical properties that have been extensively used in designing nonlinear optical materials [1-5]. Among these, heteroaryl azo dyes have recently attracted the attention of many groups due to their diverse optical applications such as second harmonic generation and optical switching [6-9].

However, one of the most important properties of these compounds is their $E-Z$ isomerization [10-11]. Typically, under UV or visible light irradiation, the thermally stable $E$ isomer is partially converted to the unstable $Z$-isomer that, in the absence of light, reverts thermally to the $E$ form following a mono-exponential kinetics (Scheme 1). This interconversion is uniquely clean, fast and efficient.

Scheme 1. E-Z photoisomerization in diaryl azo dyes.

The lifetime of the photogenerated $Z$-isomer is very relevant to practical applications: in dyeing and printing an extended $E-Z$ photo-conversion is disadvantageous since it results in a pronounced photochromic effect and weakening of the colour constancy as the $Z$-isomer absorbs at lower wavelengths. On the other hand, for more modern applications where the photoisomerization reaction is used, the control of the kinetics of the thermal back isomerization process, and therefore the lifetime of the $Z$-isomer, is essential. Ideally the conversion should be extensive and fast. Recent 
applications try to exploit not only the colour change but mainly the geometrical and electronic modifications that occur due to the $E$ - $Z$ photo-conversion. For example, when the azo dyes are incorporated in polymers the photoisomerization induces reversible conformational changes in the polymer chains, which in turn leads to macroscopic variations of the chemical and physical properties of the surroundings [12-17]. The versatility of this class of organic photoswitches has attracted the interest of many research groups and they are now used in diverse optical applications, including memories, molecular switches, photomodulation materials and molecular machines [1823].

Although a large variety of diarylazo compounds are used in the design of optical materials, only a few reports concerning the photoisomerization of heterocyclic azo dyes can be found in the literature [24-26]. Even more rare are the examples of azo dyes bearing pyrrole or thienylpyrrole systems as donor moieties, functionalized with aryl or heteroaryl diazene acceptors [2, 8, 27-30]. Recently, we have developed an efficient synthesis of heterocyclic azo dyes, through the coupling of aryl or heteroaryldiazonium salts with thienylpyrrole or bithiophene derivatives [27-28, 31-32]. The study of these chromophores showed that their solvatochromic, photochromic and nonlinear optical (NLO) properties are very dependent on the nature and substitution pattern of the aryl and heteroaryl moieties. In particular the speed of response to an external stimulus (light or absence of light), that induces the $E-Z$ azo isomerization reaction, and consequently the amplitude of the absorption variation, are strongly influenced by the electronic nature of the aromatic rings and the position of the azo linkage. While aryldiazene thienylpyrroles [33] exhibit thermal $Z \rightarrow E$ back isomerization rates around $0.30 \mathrm{~s}^{-1}$, aryldiazene bithiophenes [34] showed significant slower rates (0.01-0.04 $\left.\mathrm{s}^{-1}\right)$ indicating more stable $Z$-isomers. On the other hand the substitution of an aryldiazene moiety by a thiazolyldiazene group on thienylpyrrole derivatives led to a very significant increase on the thermal $Z \rightarrow E$ isomerization rate for thiazolyl azo dyes [28]. For the latter 
compounds the switching between the two stereoisomers can be performed in 2 to 3 seconds with a noteworthy change in the visible spectrum. In order to modulate the switching speeds of the latter system we decided to substitute the thiazole ring by a benzothiazole heterocycle which can be linked to the $\pi$-conjugated system/donor moiety through different positions. In this respect, two new series of azo benzothiazolyl thienylpyrroles 1-3 were designed and their photochromic properties evaluated. The first series is based on thienylpyrrolyl-benzothiazol-2-yl-diazenes $\mathbf{1 a - b}$ and $\mathbf{2 a}$ and, the second, on thienylpyrrolyl-benzothiazol-6-yl-diazenes 3a-c (Figure 1).

Figure 1. Structure of benzothiazole azo dyes 1-3.

\section{Results and discussion}

The synthesis of benzothiazolyl diazenes 1-3 was recently described [35]. The photochromic properties of benzothiazole azo dyes 1a-b, 2a and 3a-c were studied in $2.0 \times 10^{-5} \mathrm{M}$ acetone solutions by measuring the absorbance of the solution at the maximum wavelength of absorption while irradiating with visible light from a $150 \mathrm{~W}$ ozone free xenon lamp equipped with a water filter and a long-pass filter Schott GG 420 at $20^{\circ} \mathrm{C}$.

In acetone all compounds afforded deeply coloured solutions (yellow to purple) with molar absorptivities ranging from $1.2 \times 10^{4}$ to $3.2 \times 10^{4} \mathrm{M}^{-1} \cdot \mathrm{cm}^{-1}$. The benzothiazol-6-yl azo dyes 3a-c displayed an intense absorption maxima between 454-461 nm, while the azo dyes 1a-b, where the azo function is bonded to the thiazole ring of the benzothiazole moiety, exhibit a maximum wavelength of absorption at significantly higher wavelengths 503-515 nm.

The visible light irradiation of the 1a-b, 2a, 3a-c azo dyes solutions led to a fast decrease of the maximum absorbance at longer wavelengths and, at the same time, an increase in the band located near $380 \mathrm{~nm}$, indicating the transformation of the more stable $E$-isomer to the $Z$-isomer that absorbs at shorter wavelengths. The change in the visible spectrum of dye $\mathbf{3 b}$ is depicted in Figure 
Figure 2. Absorption spectra of dye $\mathbf{3 b}$ under visible irradiation (-----) and in the dark (- - .

When the irradiation was stopped the inverse situation was observed, the band at $380 \mathrm{~nm}$ decreased and the band at $461 \mathrm{~nm}$ increased following a monoexponential kinetics. The thermal colouration rate constants $\left(\mathrm{k}_{\Delta}\right)$ of the back $Z \rightarrow E$ isomerization reaction were then measured at $\lambda_{\max }$ and are shown in Table 1 along with the absorbance variation $(\Delta \mathrm{Abs})$ and half-life $\left(\mathrm{t}_{1 / 2}\right)$ of the $Z$ isomer.

Table 1 Spectrokinetic properties under continuous visible irradiation: maximum wavelength of absorption $\left(\lambda_{\max }\right)$, maximum absorbance $\left(\mathrm{A}_{\max }\right)$, absorbance variation $(\Delta \mathrm{Abs})$, thermal colouration rates $\left(\mathrm{k}_{\Delta}\right)$ and half-life $\left(\mathrm{t}_{1 / 2}\right)$ of azo dyes $\mathbf{1 a - b}, \mathbf{2 a}, \mathbf{3 a - c}, \mathbf{4 a}$ and $\mathbf{5 a - b}$.

From Table 1 is clear that the position of the linkage between the benzothiazole group and the azo function has a manifest influence on the photochromic properties of these compounds. While the visible irradiation of benzothiazole azo dyes 1a-b and 2a, linked through position 2 of the thiazole nucleus, induces the partial conversion of the $E$-isomer to the less stable Z-isomer, accompanied by a very small change of the absorbance (3-6\% decrease), the irradiation of benzothiazol-6-yl azo dyes 3a-c led to a more pronounced change of the absorbance (37-42\% decrease) (Figure 3).

Figure 3. Visible irradiation/dark cycles for azo dyes 1a and 3a.

This behaviour is related to the kinetics of the colouration reaction in the dark (thermal $Z \rightarrow E$ transformation). Under continuous visible irradiation conditions, the decrease in the absorbance at the $\lambda_{\max }$ of the $E$-isomer is inversely related to the kinetic rate of the colouration process $(Z \rightarrow E)$. 
Consequently, in similar systems, an increase in the thermal back colouration kinetics led to lower absorbance variations and the increase in the stability of the $Z$-isomer led to a more prominent change of the absorbance. Therefore, the $Z$-isomers of azo dyes 3a-c are more stable then those of azo dyes 1a-b and 2a. This can also be seen by comparing the half-life of these species $\left(\mathbf{3 a}-\mathbf{b}: \mathbf{t}_{1 / 2}=\right.$ 7.1-10 $\mathrm{s}$ and 1a-b: $\left.\mathrm{t}_{1 / 2}=0.50-1.54 \mathrm{~s}\right)$.

This particular system allows one to chose between two dependent characteristics. Visible light irradiation of benzothiazol-6-yl azo dyes 3a-c gives a more perceptible change in the visible spectrum while benzothiazol-2-yl azo dyes 1a-b and 2a exhibits a faster switching speed between the two isomers.

Comparing the photochromic behaviour of these new benzothiazole azo dyes with the similar thienylpyrrole azo dyes functionalized with phenyldiazene $\mathbf{4 a}$, or thiazoyldiazene $\mathbf{5 a - b}$, moieties recently reported by us [28] it can be concluded that the fusion of a thiazole ring to the azo phenyl group leads to a 3 fold increase in the colouration kinetics $(\mathbf{4 a / 3 a})$ while the anellation of a benzene ring on the thiazole azo dyes $(\mathbf{5 a}-\mathbf{b} / \mathbf{1 a}-\mathbf{b})$ decrease the thermal kinetic rate and induces a much lower absorption variation.

\section{Conclusions}

For benzothiazole azo dyes, the kinetics of the $E-Z$ transformation can be controlled by the appropriate choice of the linkage position of the benzothiazole heterocycle to the $\mathrm{N}=\mathrm{N}$ function. The linkage of the diazenyl group to the thiazole nucleus (position 2) of the benzothiazole moiety led to azo dyes exhibiting faster switching speeds between the two stereoisomers than the linkage to the benzene nucleus (position 6) of the same molecule. However, for benzothiazol-2-yl azo dyes, only a small percentage of the $E$-isomer is converted to the $Z$-isomer and thus the amplitude of the absorption variation is very small. On the other hand the parent benzothiazoles azo dyes 3a-c show 
an excellent compromise between the switching speed and percentage of $E$ - $Z$ conversion (37-42\%) leading to a strong colour variation perception.

\section{Experimental}

For measurements of $\lambda_{\max }, \mathrm{A}_{\mathrm{eq}}$ and $\mathrm{k}_{\Delta}$ under continuous visible irradiation, $2.0 \times 10^{-5} \mathrm{M}$ acetone solutions were used. Irradiation experiments were made using a CARY 50 Varian spectrophotometer coupled to a 150W ozone free xenon lamp (6255 Oriel Instruments). The light from the UV-vis lamp was filtered using a water filter (61945 Oriel Instruments) and a long-pass filter (Schott GG 420) at $20^{\circ} \mathrm{C}$ and carried to the spectrophotometer holder, perpendicular to the monitoring beam using a fibre-optic system (77654 Oriel Instruments). A thermostated $\left(20{ }^{\circ} \mathrm{C}\right) 10$ $\mathrm{mm}$ quartz cell containing the sample solution $(3.5 \mathrm{~mL})$ and equipped with magnetic stirring was used. Three spectrokinetic parameters, normally quoted when describing the properties of photochromic compounds, were evaluated: maximum wavelength of absorption $\left(\lambda_{\max }\right)$, thermal colouration rates $\left(\mathrm{k}_{\Delta}\right)$ and maximum absorbance attained at $\lambda_{\max }\left(\mathrm{A}_{\max }\right)$. The colouration kinetics were then studied in the dark. The thermal coloration curves were analysed evaluating the fitting of the experimental data to the mono-exponential equation:

$$
A(t)=A_{1} e^{-k t}+A_{0}
$$

where $A(t)$ is the absorbance at $\lambda_{\max }$ at instant $t, A_{l}$ a proportional factor, $k$ the thermal colouration rate and $A_{0}$ the absorbance in the dark when time approaches infinity. The model was found to accurately fit our data when the quadratic residual errors were $10^{-6}$ or less.

\section{Acknowledgments}

Thanks are due to the Fundação para a Ciência e Tecnologia (Portugal) and FEDER for financial support through Centro de Química - Universidade do Minho, Project PTDC/QUI/66251/2006 (FCOMP-01-0124-FEDER-007429) and research grant to M.C.R. Castro (UMINHO/BI/142/2009). 


\section{References and notes}

[1] Yesodha SK, Pillai CKS, Tsutsumi N. Stable polymeric materials for nonlinear optics: a review based on azobenzene systems. Progress in Polymer Science 2004;29:45-74.

[2] Audebert P, Kamada K, Matsunaga K, Ohta K. The third-order NLO properties of D-pi-A molecules with changing a primary amino group into pyrrole. Chemical Physics Letters 2003;367(1-2):62-71.

[3] Alicante R, Cases R, Forcen P, Oriol L, Villacampa B. Synthesis and Nonlinear Optical Properties of Side Chain Liquid Crystalline Polymers Containing Azobenzene Push-Pull Chromophores. Journal of Polymer Science part A-Polymer Chemistry 2010; 48(1):232-242.

[4] Hrozhyk UA, Serak SV, Tabiryan NV, Hoke L, Steeves DM, Kimball BR. Azobenzene liquid crystalline materials for efficient optical switching with pulsed and/or continuous wave laser beams. Optics Express 2010;18(8):8697-8704.

[5] Kleinpeter E, Bolke U, Kreicberga J. Quantification of the push-pull character of azo dyes and a basis for their evaluation as potential nonlinear optical materials. Tetrahedron 2010;66(25):45034509.

[6] Delahaye E, Sandeau N, Tao Y, Brasselet S, Clement R, Synthesis and Second Harmonic Generation Microscopy of Nonlinear Optical Efficient Hybrid Nanoparticles Embedded in Polymer Films. Evidence for Intra- and Internanoparticles Orientational Synergy. Journal of Physical Chemistry C 2009; 113(21):9092-9100. 
[7] Borbone F, Carella A, Ricciotti L, Tuzi A, Roviello A, Barsella A, High nonlinear optical response in 4-chlorothiazole-based azo dyes. Dyes and Pigments 2011; 88(3):290-95.

[8] Facchetti A, Abbotto A, Beverina L, Van der Boom ME, Dutta P, Evmenenko G, Marks TJ, Pagani GA. Azinium-(pi-bridge)-pyrrole NLO-phores: Influence of heterocycle acceptors on chromophoric and self-assembled thin-film properties. Chemistry of Materials 2002;14:4996-5005.

[9] Raposo MMM, Ferreira AMFP, Belsley M, Moura JCVP. 5 '-Alkoxy-2,2'-bithiophene azo dyes: a novel promising series of NLO-chromophores. Tetrahedron 2008;64(25):5878-5884.

[10] Wazzan NA, Richardson PR, Jones AC. Cis-Trans isomerisation of azobenzenes studied by laser-coupled NMR spectroscopy and DFT calculations. Photochemical and Photobiological Sciences 2010;9(7):968-974.

[11] Cimiraglia R, Asano T, Hofmann HJ. Mechanism of thermal Z/E isomerization of aromatic azo compounds. Relation between rotation and inversion states, Gazzetta Chimica Italiana 1996;126(10):679-684.

[12] Yager KG, Barrett CJ. Novel photo-switching using azobenzene functional materials. Journal of Photochemistry and Photobiology A: Chemistry 2006;182(3):250-261.

[13] Nabeshima Y, Shishido A, Kanazawa A, Shiono T, Ikeda T, Hiyama T. Synthesis of novel liquid-crystalline thiophene derivatives and evaluation of their photoresponsive behavior Chemistry of Materials 1997;9(6):1480-1487. 
[14] Blinov LM, Kozlovsky MV, Ozaki M, Yoshino K. Photochromism of azo-dyes and effect of liquid crystalline ordering on its efficiency and kinetics. Molecular Crystals and Liquid Crystals Science and Technology Sect C 1996;6(4):235-252.

[15] Tawa K, Kamada K, Kiyohara K, Ohta K, Yasumatsu D, Sekkat Z, Kawata S Photoinduced reorientation of azo dyes bonded to polyurethane studied by polarized FT-IR spectroscopy. Macromolecules 2001;34(23):8232-8238.

[16] Tawa K, Kamada K, Sakaguchi T, Ohta K. Local environment dependence of photoinduced anisotropy observed in azo-dye-doped polymer films. Polymer 2000;41(9):3235-3242.

[17] Keum CD, Ikawa T, Tsuchimori M, Watanabe O. Photodeformation behavior of photodynamic polymers bearing azobenzene moieties in their main and/or side chain. Macromolecules 2003;36(13):4916-4923.

[18] Towns AD. Developments in azo disperse dyes derived from heterocyclic diazo components. Dyes Pigments 1999;42(1):3-28.

[19] Åstrand PO, Sommer-Larsen P, Hvilsted S, Ramanujam PS, Bak KL, Sauer SPA. Fivemembered rings as diazo components in optical data storage devices: an ab initio investigation of the lowest singlet excitation energies. Chemical Physics Letters 2000;325(1-3):115-119.

[20] Baroncini M, Silvi S, Venturi M, Credi A. Reversible Photoswitching of Rotaxane Character and Interplay of Thermodynamic Stability and Kinetic Lability in a Self-Assembling Ring-Axle Molecular System. Chemistry-A European Journal 2010;16(38):11580-11587. 
[21] Haberhauer G, Kallweit C. A Bridged Azobenzene Derivative as a Reversible, Light-Induced Chirality Switch. Angewandte Chemie-International Edition 2010;49(13):2418-2421.

[22] Kausar A, Nagano H, Ogata T, Nonaka T, Kurihara S. Photocontrolled Translational Motion of a Microscale Solid Object on Azobenzene-Doped Liquid-Crystalline Films. Angewandte Chemie International Edition 2010;48(12):2144-2147.

[23] Russew MM, Hecht S. Photoswitches: From Molecules to Materials. Advanced materials 2010;22( 31):3348-3360.

[24] Brown E, Granneman G. Cis-trans isomerism in pyridyl analogs of azobenzene - kinetic and molecular-orbital analysis. Journal of the American Chemical Society 1975;97:621-627.

[25] Barachevsky VA, Oliveira-Campos AMF, Stebunova LV, Chudinova LV, Avakyan VG, Maslyanitsyn IA, Shigorin VD. Thienothiazole azo dyes: Photochromism and nonlinear behavior. Zh. Nauchii Prikladnoi Fotografii 2002;47:4-8.

[26] Otsuki J, Suwa K, Narutaki K, Sinha C, Yoshikawa I, Araki K. Photochromism of 2(phenylazo)imidazoles. Journal of Physical Chemistry A 2005;109:8064-8069.

[27] Raposo MMM, Sousa AMRC, Fonseca AMC, Kirsch G. Thienylpyrrole azo dyes: synthesis, solvatochromic and electrochemical properties. Tetrahedron 2005;61:8249. 
[28] Raposo MMM, Fonseca AMC, Castro MCR, Belsley M, Cardoso MFS, Carvalho LM, Coelho

PJ. Novel diazenes bearing pyrrole, thiophene and thiazole heterocycles as efficient photochromic and nonlinear optical (NLO) materials Dyes Pigments 2011;91:62-73

[29] Trofimov BA, Schmidt EY, Mikhaleva AI, Vasiltsov AM, Zaitsev AB, Smolyanina NS, Senotrusova EY, Afonin AV, Ushakov IA, Petrushenko KB, Kazheva ON, Dyachenko OA, Smirnov VV, Schmidt AF, Markova MV, Morozova L. 2-Arylazo-1-vinylpyrroles: A novel promising family of reactive dyes. European Journal of Organic Chemistry 2006;17:4021-4033.

[30] Yen MS, Chen CW. The synthesis of vinyltriethoxysilane-modified heteroaryl thiazole dyes and silica hybrid materials. Dyes and Pigments 2010;86(2):129-132.

[31] Raposo MMM, Ferreira AMFP, Belsley M, Moura JCVP. 5’-Alkoxy-2,2`-bithiophene azo dyes: a novel promising series of NLO chromophores. Tetrahedron 2008;64:5878.

[32] Raposo MMM, Ferreira AMFP, Amaro M, Belsley M, Moura JCVP. The synthesis and characterization of heterocyclic azo dyes derived from 5-N,N-dialkylamino-2,2'-bithiophene couplers. Dyes Pigments 2009;83:59-65.

[33] Coelho PJ, Carvalho LM, Fonseca AMC, Raposo MMM. Photochromic properties of thienylpyrrole azo dyes in solution. Tetrahedron Lett. 2006;47(22):3711-14.

[34] Coelho PJ, Carvalho LM, Moura JCVP, Raposo MMM. Novel photochromic 2,2'-bithiophene azo dyes. Dyes Pigments 2009;82:130-133 
[35] Raposo MMM, Castro MCR, Fonseca AMC, Schellenberg P, Belsley M. Design, synthesis and characterization of electrochemical, nonlinear optical (NLO) properties and theoretical studies of novel thienylpyrrole azo dyes bearing benzothiazole acceptor groups. Tetrahedron 2011. DOI: 10.1016/j.tet.2011.05.053.

\section{Graphical abstract}

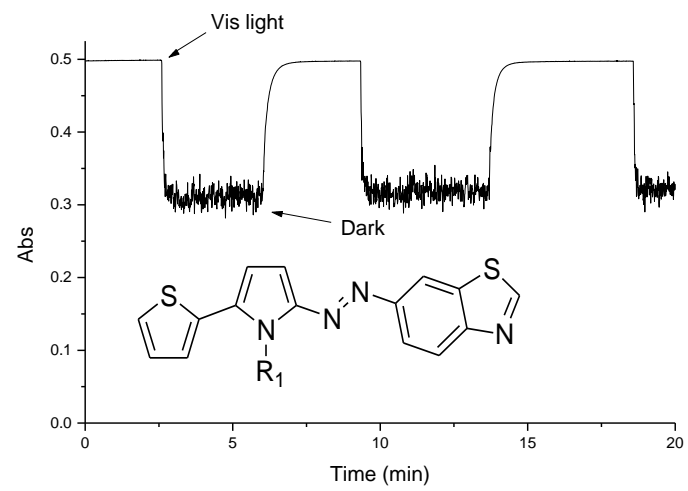

$$
\begin{aligned}
& \operatorname{Ar}^{\prime}=N^{\prime} \quad \frac{\mathrm{hu}_{1}}{\Delta \mathrm{orhu}_{2}} \quad \mathrm{Ar}^{\prime} \mathrm{Ar}^{\mathrm{N}=\mathrm{N}} \\
& E \text { - isomer } \quad Z \text { - isomer }
\end{aligned}
$$

Scheme 1. E-Z photoisomerization in diaryl azo dyes. 

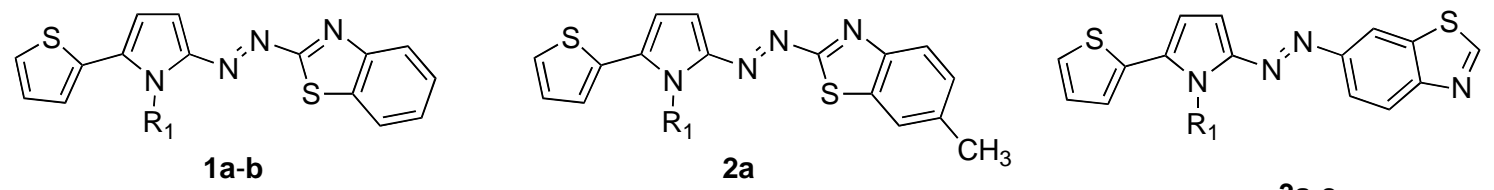

3a-c

$$
\begin{array}{ll}
\text { a } & \mathrm{R}_{1}=n-\mathrm{Pr} \\
\text { b } & \mathrm{R}_{1}=4-\mathrm{MeOC}_{6} \mathrm{H}_{4} \\
\text { c } & \mathrm{R}_{1}=4-\mathrm{FC}_{6} \mathrm{H}_{4}
\end{array}
$$

Figure 1. Structure of benzothiazole azo dyes 1-3.

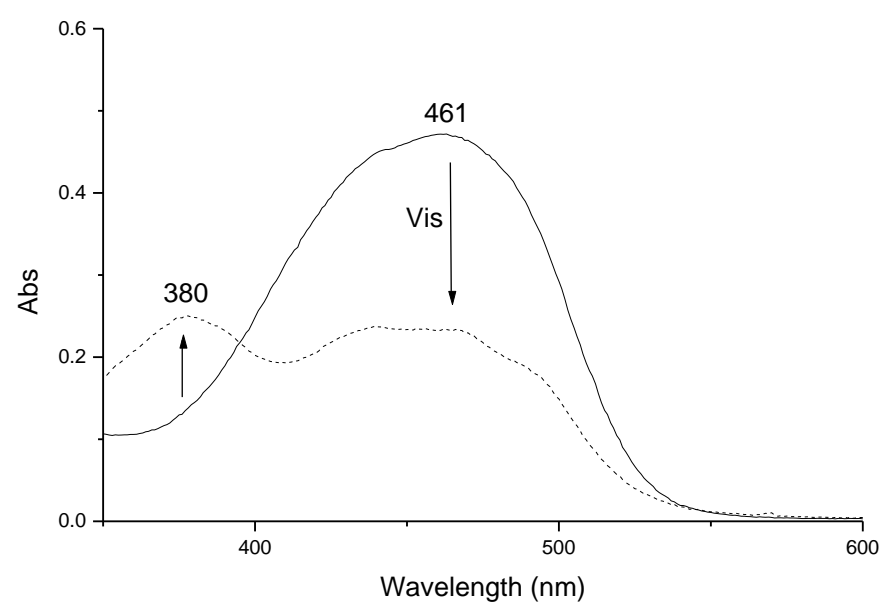

Figure 2. Absorption spectra of dye $\mathbf{3 b}$ under visible irradiation (-----) and in the dark (-). 

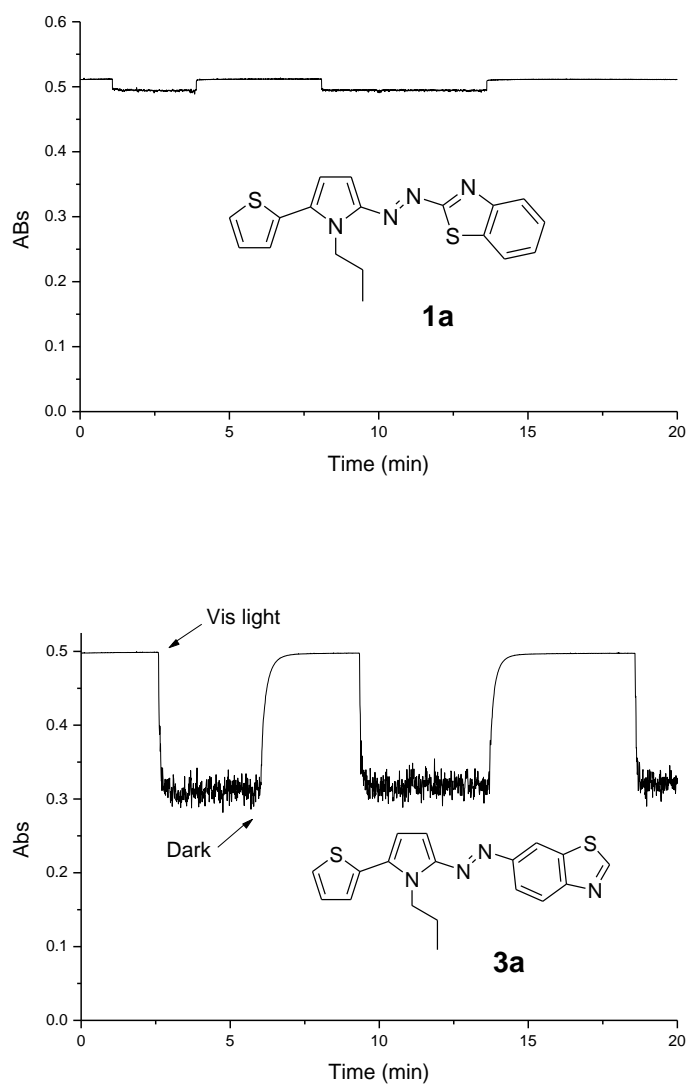

Figure 3. Visible irradiation/dark cycles for azo dyes 1a and 3a. 
Table 1 Spectrokinetic properties under continuous visible irradiation: maximum wavelength of absorption $\left(\lambda_{\max }\right)$, maximum absorbance $\left(\mathrm{A}_{\max }\right)$, absorbance variation $(\Delta \mathrm{Abs})$, thermal colouration rates $\left(\mathrm{k}_{\Delta}\right)$ and half-life $\left(\mathrm{t}_{1 / 2}\right)$ of azo dyes $\mathbf{1 a - b}, \mathbf{2 a}, \mathbf{3 a - c}, \mathbf{4 a}$ and $\mathbf{5 a - b}$.

\begin{tabular}{|c|c|c|c|c|c|c|}
\hline Azo dye & $\mathrm{R}_{1}$ & $\lambda_{\max } / \mathrm{nm}$ & $\mathrm{A}_{\max }$ & $\Delta \operatorname{Abs}(\%)$ & $\mathrm{k}_{\Delta} / \mathrm{s}^{-1}$ & $\mathrm{t}_{1 / 2} / \mathrm{s}$ \\
\hline & $n-\operatorname{Pr}$ & 503 & 0.258 & $0.010(3.7 \%)$ & 0.45 & 1.54 \\
\hline $1 \mathrm{~b}$ & 4- $\mathrm{MeOC}_{6} \mathrm{H}_{4}$ & 515 & 0.512 & 0.017 (3.3\%) & 1.4 & 0.50 \\
\hline & $n-\operatorname{Pr}$ & 507 & 0.495 & $0.029(5.8 \%)$ & 1.2 & 0.58 \\
\hline & $n-\operatorname{Pr}$ & 454 & 0.498 & $0.185(37 \%)$ & 0.098 & 7.1 \\
\hline $3 \mathbf{b}$ & 4- $\mathrm{MeOC}_{6} \mathrm{H}_{4}$ & 461 & 0.541 & $0.229(42.3 \%)$ & 0.068 & 10 \\
\hline $3 c$ & 4- $\mathrm{FC}_{6} \mathrm{H}_{4}$ & 457 & 0.656 & $0.263(40 \%)$ & 0.12 & 5.6 \\
\hline & $n-\operatorname{Pr}[28]$ & 420 & 0.523 & $0.277(53 \%)$ & 0.036 & 20 \\
\hline & $n-\operatorname{Pr}[28]$ & 487 & 0.592 & $0.121(20.4 \%)$ & 1.4 & 0.50 \\
\hline $5 b$ & $4-\mathrm{MeOC}_{6} \mathrm{H}_{4}[28]$ & 499 & 0.542 & $0.120(22 \%)$ & 0.82 & 0.85 \\
\hline
\end{tabular}

